\title{
SER QUILOMBOLA: PRÁTICAS CURRICULARES \\ EM EDUCAÇÃO DO CAMPO
}

\author{
Iris Verena Oliveira (UNEB)*
}

\begin{abstract}
RESUMO
Este artigo apresenta um relato da aproximação com o campo na pesquisa sobre currículo e formação de professores que atuam nas escolas quilombolas em Conceição do Coité e Nordestina, no Território do Sisal, na Bahia. O intuito é problematizar questões relacionadas à educação e relações raciais em práticas curriculares, propondo intersecções entre educação do campo e educação escolar quilombola. Para tanto, buscou-se, por meio de abordagem qualitativa, com o uso de entrevistas e observação participante, alinhavar fios que despontaram em situações distintas, evidenciando fazeres curriculares que rasuram construções identitárias em torno do ser quilombola. O relato chama atenção para o tratamento de questões raciais na educação do campo, ao tempo em que mostra a limitação do debate sobre currículo na educação escolar quilombola, quando o foco se volta apenas para a inclusão de conteúdos. Propõe tratar a diferença pelo viés pós-colonial e pós-estruturalista, considerando as práticas curriculares em oblíquas tramas de poder, nas quais o ser quilombola desliza cotidianamente.
\end{abstract}

Palavras-chave: Educação Escolar Quilombola. Educação do Campo. Currículo.

\begin{abstract}
BEING QUILOMBOLA: CURRICULUM PRACTICES IN FIELD EDUCATION

This article presents an account of an approach with field in research about teacher's curriculum and formation that act in quilombolas schools in Conceição do Coite and Nordestina, in the Territory of Sisal, Bahia. The intention is problematize issues related to education and racial relationships in curriculum practices, proposing intersectionality between rural education and quilombola school education. For this purpose, we sought, through an a qualitative approach, with the use of interviews and participant observation, plotting yarns that came up in different situations, that emphasize curriculum practices that erasure identity constructions, around being quilombola. The account warns to the treatment of racial issues at rural education, at time that shows the limitation of discussions about curriculum at quilombola school education; when the focus turns just to content inclusion. We propose treat the difference by the postcolonial and post-structuralism slant, seeing the curriculum practices in oblique plots of power, which being quilombola daily slides.
\end{abstract}

Keywords: Quilombola school education. Rural Education. Curriculum.

\footnotetext{
* Doutora em Estudos Étnicos e Africanos pela Universidade Federal da Bahia (PÓS-AFRO/UFBA). Professora do Departamento de Educação - Campus XIV/UNEB/Conceição do Coité (Bahia). Bolsista do Programa Nacional de Pós-Doutorado/ CAPES-UERJ. Professora do Mestrado Profissional em Educação da Universidade Federal da Bahia (MPED/FACED/UFBA). Membro dos grupos de pesquisa FEL/UNEB/CNPq e FEP/UFBA/CNPq. E-mail: irisveren@gmail.com
} 


\section{RESUMEN}

\section{SER QUILOMBOLA: PRÁCTICAS CURRICULAR EN EDUCACIÓN DEL CAMPO}

El artículo presenta un relato de la aproximación con el campo en la investigación sobre currículo y formación de profesores que actúan en las escuelas quilombolas en Conceição do Coité y Nordestina, en el Territorio del Sisal, en Bahía. La intención es problematizar cuestiones relacionadas a la educación y relaciones raciales en prácticas curriculares, proponiendo intersecciones entre educación del campo y educación escolar quilombola. Para ello, se buscó, por medio de abordaje cualitativo, con el uso de entrevistas y observación participante, alinea los hilos que despuntaron en situaciones distintas, evidenciando haceres curriculares que rasuran construcciones identitarias alrededor del ser quilombola. El relato llama la atención sobre el tratamiento de cuestiones raciales en la educación del campo, al tiempo que muestra la limitación del debate sobre currículo en la educación escolar quilombola, cuando el foco se vuelve sólo a la inclusión de contenidos. Propone tratar la diferencia por el sesgo poscolonial y post-estructuralista, considerando las prácticas curriculares en oblicuas tramas de poder, en las cuales el ser quilombola desliza cotidianamente.

Palabras clave: Educación Escolar Quilombola. Educación del Campo. Currículo.

\section{"Descobriram que a gente era quilombola"}

A preocupação com o tratamento dado às questões étnico-raciais na educação do campo foi sendo delineada a partir do desenvolvimento de atividades envolvendo escolas, de Nordestina e Conceição do Coité, no Território do Sisal, na Bahia. Por isso, optou-se por descrever as situações de pesquisa que geraram as questões, posteriormente problematizadas em diálogo com a bibliografia relacionada à temática. A observação participante possibilitou vivenciar situações em que sensações, dúvidas e frustrações desenharam no itinerário da pesquisa, em um exercício que buscou atentar à subjetividade dos envolvidos.

Os cenários formativos analisados na pesquisa foram as redes municipais de educação de Nordestina e Conceição do Coité. Atualmente, no Território do Sisal, existem 18 comunidades quilombolas certificadas ${ }^{1}$ pela Fundação Cultural Palmares e mais

\footnotetext{
1 A Portaria n ${ }^{\circ} 98$ da Fundação Cultural Palmares (2007) informa as condições para a emissão da certidão de autodefinição: "Art $3^{\circ}$ Para a emissão da certidão de autodefinição como remanescente dos quilombos deverão ser adotados os seguintes procedimentos: I - A comunidade que não possui associação legalmente constituída deverá apresentar ata de reunião convocada para específica finalidade de deliberação a respeito da autodefinição, aprovada pela maioria de seus moradores, acompanhada de lista de presença devidamente assinada; II - A comunidade que possui associação legalmente
}

duas com processos pendentes. Sem contar aquelas outras que ainda não conseguiram se organizar para cumprir a burocracia ${ }^{2}$ exigida para a certificação.

As informações disponibilizadas pela Fundação Cultural Palmares chamam atenção, pois a meta-narrativa histórica destacou a presença marcante da população negra em Salvador e no recôncavo baiano; só recentemente as pesquisas têm apresentado as dinâmicas da escravidão em outros espaços do estado. Por outro lado, a baianidade nagô cantada em verso e prosa pela música e pela literatura amadiana generalizam referências que compõem o mapa turístico da Bahia, contribuindo para a invisibilização das peculiaridades de outros cenários. Nas cidades do Território do Sisal,

constituída deverá apresentar ata da assembleia convocada para específica finalidade de deliberação a respeito da autodefinição, aprovada pela maioria absoluta de seus membros, acompanhada de lista de presença devidamente assinada; III- Remessa à FCP, caso a comunidade os possua, de dados, documentos ou informações, tais como fotos, reportagens, estudos realizados, entre outros, que atestem a história comum do grupo ou suas manifestações culturais; IV - Em qualquer caso, apresentação de relato sintético da trajetória comum do grupo (história da comunidade); V - Solicitação ao Presidente da FCP de emissão da certidão de autodefinição". Fundação Cultural Palmares (2017).

2 Decreto $\mathrm{n}^{\circ} 4.887 / 2003$, que regulamenta os processos que vão do reconhecimento até a titulação das terras (BRASIL, 2003). 
os textos memorialísticos não reivindicam uma pertença fortemente alicerçada na herança e ancestralidade da população negra, só recentemente as investigações sobre a escravidão ganharam fôlego. Os registros de compra e venda de cativos, assim como os testamentos, indicam que era comum na região que os proprietários tivessem entre um e três escravos (SOUZA, 2016).

A documentação levantada até o momento cartas de alforria, inventários, livros de batismo e casamento - indica que ocorria uma feira voltada para a venda e a compra de escravos, tornando a cidade um importante centro comercial para a região, por onde passavam cativos para outras províncias, o que leva a supor que ela possuía situação semelhante quanto à predominância de escravizados brasileiros e organização em grupos pequenos nas propriedades rurais (RIOS, 2003; GORDIANO, 2011).

Nesse sentido, as narrativas de memorialistas do Território do Sisal construíram outras ficções relacionadas à trajetória daquela população; nelas se destacam o passado longínquo dos índios, imagens tradicionalmente vinculadas ao sertão e, mais recentemente, a importância das atividades ligadas ao cultivo e manufatura de uma planta característica da região. Portanto, identificar 18 comunidades certificadas como quilombolas pela Fundação Cultural Palmares é impressionante em um Território cuja maioria da população não reivindica pertencimento étnico vinculado à negritude.

Nos municípios, a aproximação com as escolas foi intermediada pelos movimentos sociais, cujas representações anseiam pelo tratamento das questões raciais nos espaços escolares. Nas reuniões ouviu-se a fala recorrente das lideranças sobre a falta de consciência da negritude. Aos poucos foi possível compreender que se estabelecia uma relação direta entre pertencimento étnico e organização de movimentos como blocos afro, afoxés e outras práticas culturais presentes em outras cidades do estado. Desconsiderando as peculiaridades do processo de ocupação desse espaço, que atendem a características históricas e culturais diferentes de Salvador.

Entender as especificidades do Território do Sisal fez-se necessário para dizer que, frequentemente, quando as lideranças comunitárias se refe- rem à falta de consciência do que é ser quilombola, ou ainda, que as pessoas das comunidades não têm orgulho de sua negritude, elas tomam como referência o processo de empoderamento tal qual ocorreu em outras regiões. Sem considerar que as cidades do Território não contam com as narrativas de ancestralidade, fundadas na história, legitimando suas construções identitárias.

Ao final de algumas visitas realizadas nas comunidades, foi possível observar o olhar frustrado das graduandas da Universidade do Estado da Bahia - Campus de Conceição do Coité, que compõem a equipe do projeto de extensão. A expectativa era de que as comunidades tivessem diversos terreiros de candomblé; que ouvissem narrativas contadas de avó para netos das crueldades dos tempos da escravidão; e que as crianças esbanjassem um sentimento de orgulho étnico que confrontassem os currículos eurocêntricos de suas escolas. Justamente o que não foi encontrado!

Vale destacar que as estudantes que atuam no projeto nasceram no Território do Sisal, o que não lhes impediu de construir uma idealização do que seria um quilombo. Em alguns casos, elas já conheciam as localidades, mas não sabiam que eram comunidades quilombolas. Logo, questiona-se o tratamento dado a essas questões na sua formação inicial e o contato com a memória e história local nos anos em que estiveram na educação básica. $\mathrm{O}$ que evidencia a necessidade de propor uma formação de professores que problematize a construção discursiva das experiências nas comunidades quilombolas, atentando para esta constituição em suas práticas curriculares.

$\mathrm{Na}$ aproximação com o campo de pesquisa atentou-se para os significados atribuídos pelos moradores da comunidade ao termo "quilombola", por vezes referido como "quirombola", ao tempo em que se observou as expectativas que envolviam os(as) pesquisadores(as) da equipe, entre os(as) quais a autora se inclui. Para tanto, conversas informais, perguntas não compreendidas e respostas inusitadas compõem a rede de indícios seguida na pesquisa, assumindo a recomposição de sentidos inerente à prática interpretativa da etnografia (MESSEDER, 2013).

Faz-se necessário chamar atenção para a proximidade temporal dessa pesquisa em relação ao 
momento em que as comunidades quilombolas conquistaram as certificações, entre 2006 e 2014, ou seja, considerando que muitas pessoas atentaram para o termo "quilombo" somente durante a produção do material enviado para a Fundação Cultural Palmares, trata-se de um processo que está sendo vivenciado atualmente pelos(as) moradores(as).

É importante registrar que a necessidade de autoafirmação como quilombola tem gerado inúmeros conflitos internos nas comunidades; ainda que essa questão mereça maior densidade etnográfica, é ilustrativa a fala de um professor da rede municipal sobre a condução do processo na comunidade quilombola em que ele reside. Quando questionado se houve a participação dos moradores, ele diz:

Participaram... tinha um padre aqui que era padre Miguel, ele era da Espanha. Então, ele entrou em contato com [Senhor do] Bomfim e descobriu uma comunidade quilombola. Pediu pra um rapaz que é de lá, o Valmir, da comunidade Tijuaçu, ir fazer uma palestra com a gente. Aí ele veio, aí de repente descobriram que a gente era quilombola! Vamos dizer assim; aí fez todo um trabalho, reuniu um monte de gente, abriu uma associação onde eu era presidente mais uma menina. [...] A gente passou por esse processo de pessoas mais velhas tá contando as histórias como foi, até que houve uma resistência do pessoal mais velho: 'Ah! Vai voltar a escravidão de novo?' Quando chegava na porta, eles fechavam a porta. (PAULO). ${ }^{3}$

Fica implícito na fala de Paulo os agenciamentos conduzidos no processo político, que levam a comunidade a "descobrir" que era quilombola, provavelmente associados à luta por direitos. Entretanto, isso não significou uma aceitação unânime por parte dos moradores, em especial para os mais velhos da comunidade. É possível que eles tenham sentido uma dificuldade maior na positivação de elementos que historicamente foram acionados para desqualificar e estereotipar as populações negras.

\section{"Só podia ser o(a) neguinho(a) do Maracujá!"}

Em 2013, a professora Rosane Vieira coor-

\footnotetext{
3 O nome das instituições de ensino e dos entrevistados não serão divulgados, com o intuito de evitar quaisquer constrangimentos para as pessoas envolvidas.
}

denava, no campus $\mathrm{XIV}^{4}$ da UNEB, o Projeto de Pesquisa "Tecnologia social da memória e experiência videográfica na comunidade quilombola do Maracujá", em Conceição do Coité. A integração a este grupo de pesquisadores ocorreu para acompanhamento de bolsistas, que recolhiam narrativas de pessoas idosas da comunidade. Nelas eram remontadas práticas e trajetórias dos primeiros moradores do povoado. O "Projeto Maracujá", como era denominado comumente, resultou no curta-metragem \#vamosfazerumfilme?, cujas reuniões de planejamento, gravações e avaliações envolviam todos os pesquisadores.

A proposta do Projeto Maracujá envolvia a realização de oficinas sobre história de vida e memória, fotografia, roteiro e edição de vídeo. $\mathrm{O}$ intuito era a formação dos jovens que conduziram a realização de entrevistas com os moradores mais antigos da comunidade. A partir disso, as narrativas eram organizadas na linguagem videográfica, buscando contar as histórias pela perspectiva dos moradores.

Em uma das avaliações do projeto, após uma sequência de filmagens, ocorreu uma divergência entre a equipe e os adolescentes do Maracujá. Os jovens queriam a gravação de algumas cenas na escola em que estudavam, localizada no povoado vizinho. A equipe resistia por conta do desgaste na condução dos equipamentos e questões como o barulho da escola, problemas com direitos de imagem dos jovens, entre outras dificuldades. Em meio às discussões, um dos adolescentes relatou 0 seu incômodo com o lugar que ocupavam na escola. Segundo ele, sempre que alguma confusão ocorria na escola, envolvendo estudantes daquela comunidade quilombola, eles ouviam dos professores: "Só podia ser o(a) neguinho(a) do Maracujá!"

Durante o período em que o curta foi gravado, a comunidade ainda não havia recebido da Fundação Cultural Palmares a certificação como quilombola. A equipe do projeto retornou à comunidade na data da cerimônia. Momento em que a prefeitura municipal montou stands e ofereceu serviços de assistência social, aferição de pressão arterial, entre outros, que geralmente os moradores só acessavam na sede de Conceição do Coité. À noite, logo após a entrega do título, uma banda foi convidada para

4 O campus XIV fica localizado na cidade de Conceição do Coité, no Território do Sisal, que compõe a região Nordeste da Bahia. 
tocar no palco improvisado em frente à escola da comunidade.

O grupo tocou músicas de blocos afros que embalaram os carnavais de Salvador na década de 1990, com destaque para o Olodum e o Ilê Aiyê. As canções tratavam do empoderamento da população negra, da força das mulheres e da necessidade de enfrentamento ao racismo. Os moradores do Maracujá assistiam e conversavam, sem demonstrar interesse em relação às músicas tocadas no palco.

$\mathrm{Na}$ sequência, se apresentou um grupo de samba de roda que veio prestigiar a festa. Os músicos moravam no povoado vizinho e, por vezes, tocavam na comunidade. As cantigas entoadas eram acompanhadas com palmas e muita dança. A situação vivenciada naquela noite reportou à gravação da sequência de cenas no samba de roda, no curta-metragem feito pelos adolescentes. No filme, os mais velhos entrevistados repetiram várias vezes que os jovens não se interessavam pelas práticas culturais da comunidade, que não queriam aprender as orações das rezadeiras nem a tocar e cantar o samba de roda. Contudo, quando o samba iniciou na festa que marcou o fim das gravações no Maracujá e também a cerimônia de certificação da comunidade, os estudantes dançaram e cantaram com a naturalidade de quem fez isso a vida inteira.

A relação entre os moradores do Maracujá e o samba de roda era diferente da estabelecida com o samba reggae soteropolitano e o samba de roda do recôncavo. Essas situações fizeram emergir a pergunta feita por Stuart Hall (2003): “que 'negro' é esse na cultura negra?" Ele questiona a leitura que fixa autenticidade nas práticas culturais, preferindo entendê-las como espaços performáticos gestados "criticamente pelas condições diaspóricas" (HALL, 2003, p. 324) Afasta-se da diferença como entidade fechada, que não considera os cenários de disputa, como destacam Duschatzky e Skliar (2011, p. 127):

Esse mito da consistência cultural supõe que todos os negros vivem a negritude do mesmo modo, que os muçulmanos experimentam uma única forma cultural, que as mulheres vivem o gênero de forma idêntica. Em poucas palavras, que cada sujeito adquire identidades plenas a partir de únicas marcas de identificação, como se por acaso as culturas se estruturassem independentemente de relações de poder e hierarquia.

Nesse sentido, a atitude de levar o samba reggae para uma comunidade quilombola e ter a expectativa de que a população se sinta familiarizada com as músicas é semelhante à do pesquisador, que parte do pressuposto que encontrará um grupo de pessoas que combatem cotidianamente o racismo e sentem-se orgulhosos do seu pertencimento étnico, por terem nascido em comunidades quilombolas. Desconsideram-se, muitas vezes, as experiências de opressão e as dificuldades de problematizar as desigualdades em ambientes nos quais os desafios são tratados como individuais, como se não integrassem hierarquias históricas, sociais e raciais.

No entanto, o exercício etnográfico impõe uma tarefa árdua no estabelecimento de relações com o outro, que envolvem expectativas de ambos os lados. Na formação para construir do roteiro do curta-metragem no Maracujá, estava claro para os pesquisadores que a modalidade escolhida seria um documentário; afinal, para eles, interessava destacar a história da comunidade e marcar o papel da tradição na preservação das práticas culturais. Os adolescentes, por sua vez, não sentiram motivação alguma para atuar em um documentário. Eles queriam um filme com roteiro semelhante ao da novela "Malhação". 5 A saída encontrada foi a realização de um docudrama, uma narrativa ficcional com marcas memorialísticas. As práticas culturais que faziam parte do cotidiano rasuraram a ficção, afinal eram os corpos dos meninos e meninas do Maracujá que estavam ali; eram as narrativas dos seus familiares, as músicas do samba de roda que ouviam sempre, o que lhes permitiu esquecer as câmeras por alguns instantes.

Nos momentos da construção do roteiro e carac-

5 A novela Malhação tem sido exibida há alguns anos pela Rede Globo de televisão. A trama inicialmente desenrolava-se em uma academia de musculação e em uma de suas reformulações passou a ter como cenário uma escola na qual se desenrolam narrativas de adolescentes de classe média alta e brancos. Anualmente o elenco é substituído, mas o formato permanece: espaços como escola, repúblicas estudantis e lanchonetes nos quais de desenrolam histórias de amor que enfrentam obstáculos, vencidos ao final pela força do sentimento que envolve os protagonistas. Inicialmente, na construção dos personagens do filme do Maracujá, os jovens descreveram o personagem principal, João Paulo, como um menino branco. Somente no momento da decisão sobre quem assumiria cada personagem, se deram conta que entre eles não havia um menino com aquele perfil. 
terização dos personagens para o curta-metragem, assim como na comemoração pela certificação da comunidade, vieram à tona os realinhamentos e negociações culturais que evidenciaram os lugares híbridos ocupados pelos envolvidos (BHABHA, 2010). Se isso ocorreu em um projeto executado em dois anos na comunidade, o que dizer das escolas que estão instaladas nesses espaços ou que recebem a maior parte desses estudantes?

Ao atentar para esses aspectos em teses e dissertações produzidas sobre educação escolar quilombola, foi bastante comum encontrar hipóteses de que os currículos escolares silenciam a voz dos moradores das comunidades quilombolas, ignorando os seus saberes tradicionais (FERREIRA, 2014; SANTANA, 2015). Diante disso, fica a questão: que negritude é essa que estamos buscando nas comunidades quilombolas? Como é possível pensar em escolas localizadas dentro dessas comunidades, com $95 \%$ de estudantes quilombolas, e que não se contaminaram com o seu entorno? Seguir por aí é não considerar que "professores e alunos tecem alternativas práticas com os fios que as redes das quais fazem parte, dentro e fora da escola, lhe fornecem" (FERRAÇO; NUNES, 2013, p. 84).

Insistir nos silêncios não seria incluir para excluir? Ou seja, ao enfatizar a escola desejada, não se nega práticas curriculares prenhes do cotidiano das comunidades, que não correspondem às expectativas de negritude dos pesquisadores(as), e que já ocorrem em comunidades e/ou escolas quilombolas? O que fica de fora diante do esforço para mostrar o que falta?

Os caminhos trilhados até o momento na pesquisa indicam que a dificuldade em enxergar/tratar as práticas que já permeiam o cotidiano escolar estaria relacionada à entrada desses saberes na escola por outras vias, que não os instrumentos normativos planejados previamente pelo protocolo escolar. Em outras palavras, as dificuldades estariam em sistematizar o que não consta na lista de conteúdos, no livro didático ou o que não ficaria registrado no diário de classe. Nos termos de Inez Carvalho (1992), a insistência em tratar da escola como deveria ser tem deixado de lado o a-con-te-cer da formação nas escolas quilombolas.

O apego dos pesquisadores aos conteúdos escolares e a sua recusa diante do tratamento da cultura afro-brasileira não estariam relacionados à dificuldade para registrar festas, feiras, oficinas e desfiles na mesma perspectiva da normatização? Nesse sentido, é perceptível o esforço em denunciar a folclorização de práticas culturais quilombolas nas escolas, entretanto, as produções sobre o tema ainda apresentam uma leitura que fixa identidades e idealiza as comunidades.

Estabelecendo uma relação com as situações vividas no Projeto Maracujá, as questões acima se referem ao cuidado para não impor o samba reggae como expressão de negritude, afinal, se a equipe de pesquisa tivesse negado a possibilidade de construção de uma narrativa romântica no docudrama, provavelmente teria jogado junto com a água da bacia a implicação dos adolescentes com o samba de roda, que emergiu diante dos pesquisadores, a despeito das falas saudosistas dos idosos da comunidade.

Diante do exposto, faz-se necessário questionar: o que buscamos ao adentrar as comunidades quilombolas? Seriam características semelhantes às descritas por Abdias do Nascimento em Quilombismo, tomando Palmares como referência?

Estabeleceram o primeiro governo de africanos livres nas terras do Novo Mundo, indubitavelmente um verdadeiro Estado africano - pela forma de sua organização socioeconômica e política - conhecido na história como República de Palmares. [...] Essa terra pertencia a todos os palmarinos, e o resultado do trabalho coletivo também era propriedade comum. Os autolibertos africanos plantavam e colhiam uma produção agrícola diversificada, diferente da monocultura vigente na colônia; permutavam os frutos agrícolas com seus vizinhos brancos e indígenas. (NASCIMENTO, 2002, p. 45-46).

Na década de 1980, movidos pela proximidade do centenário da abolição, as discussões sobre resistência negra retomaram com grande força para o cenário político e acadêmico. De forma emblemática, o artigo 68 das Disposições Constitucionais Transitórias da Constituição de 1988 pontuava: "Aos remanescentes das comunidades dos quilombos que estejam ocupando suas terras é reconhecida a propriedade definitiva, devendo o Estado emitir-lhes os títulos respectivos" (MORAES, 2000, p. 151). Contudo, somente em 1995 a regulamentação desse artigo foi aprovada, em decorrência das dis- 
putas ligadas ao termo quilombo e seus derivados, que foi se consolidando na literatura como símbolo de resistência (ARRUTI, 1997).

Tendo em vista as trajetórias das populações negras do Território do Sisal, assim como os cenários de disputa das diferenças que envolvem moradores(as), professores(as) e estudantes, propõe-se problematizar a atuação dos docentes no deslizamento dos termos quilombo e quilombola, por entender que as práticas curriculares são produzidas nessa contingência.

Durante as primeiras reuniões com lideranças das comunidades quilombolas do Território, repetiu-se reiteradas vezes que o processo de reconhecimento delas teria ocorrido de forma inversa. Em outras palavras, havia o interesse das prefeituras que as comunidades fossem certificadas, possibilitando, assim, o acesso a recursos federais. Todavia, as reuniões não envolveram debates sobre identidade negra ou sobre quilombos como espaços de resistência. Para algumas lideranças dos movimentos sociais locais, as demandas para a certificação deveriam ter partido da comunidade e não dos poderes públicos.

E isso conduz ao debate sobre o ser quilombola. Para muitos moradores, esse termo apareceu pela primeira vez nas reuniões das associações, momento em que foram elencadas as vantagens de ser favorável ao reconhecimento. Isso era necessário, afinal, entre os documentos exigidos pela Fundação Cultural Palmares, consta a ata da associação de moradores, na qual estes afirmavam que eram remanescentes quilombolas. Ademais, para a mobilização de memórias da comunidade, assim como o registro de práticas culturais e entrevistas, a participação deles foi imprescindível.

Isso significa que, mesmo quando a mobilização partiu do Poder Executivo, as comunidades - por motivos diversos - construíram estratégias de mobilização de memórias e tradições culturais, ou seja, se constituíram discursivamente a partir de memórias e tradições, em prol da certificação.

Nesse movimento, o ser quilombola desliza entre o que está presente no imaginário acadêmico, "modelo de luta e militância negra" - algo positivo e que, segundo dizem os de fora, seria motivo de orgulho -, e ser "o(a) neguinho(a) do Maracujá". A proposição do deslizamento conduz a "um 'devir- -espaço' do tempo, um 'devir-tempo' do espaço, uma referência à alteridade, a uma heterogeneidade que não é primordialmente oposicional. Daí uma certa inscrição do mesmo, que não é idêntico, como différance" (DERRIDA; ROUDINESCO, 2004, p. 34). É nesse limiar, nessa fronteira, que a escola se encontra! No rastro em que o ser quilombola desliza e, ao considerar as práticas curriculares na arena com oblíquas tramas de poder, emergem os efeitos desses deslizamentos na atuação cotidiana dos professores (MACEDO, 2006).

Ainda que as dúvidas tenham permanecido sobre a definição do termo quilombola, para muitas famílias, assumir essa pertença, com a sua participação no processo de reconhecimento da comunidade, significou uma reescrita na contingência, relacionada a possibilidades de acesso a recursos, que não invalidou os estigmas atribuídos a estas, especialmente pelos que residem na sede do município.

É estruturante, portanto, entender o termo quilombola pelo viés pós-colonial, já que este "questiona as tradições teleológicas de passado e presente e a sensibilidade polarizada historicista do arcaico ao moderno" (BHABHA, 2010, p. 217) Nesse sentido, interessa compreender os efeitos, pensados em meio às negociações da diferença performaticamente produzidas nas práticas curriculares das escolas quilombolas.

Para pensar essas performances curriculares, a discussão em torno da educação e relações étnico-raciais que vem sendo desenvolvida no Brasil pode apresentar algumas pistas. Há algum tempo essa tem sido uma preocupação de diversos pesquisadores, em investigações que sofreram considerável incremento após a aprovação da Lei 10.639/03, que alterou a Lei de Diretrizes e Bases da Educação, em 1996. Algumas pesquisas se voltaram para o tratamento dado pela escola às práticas afro-brasileiras, como a dissertação desenvolvida por Marluce Macedo sobre as escolas públicas do município de Santa Bárbara, no interior da Bahia. Para a autora, “escondeu, negou, reduziu a um 'cantinho' e estereotipou os saberes e vivências da tradição oral afro-brasileira" (MACEDO, 2004, p. 130).

Outras produções acadêmicas preocuparam-se com a formação de professores para a implementação da lei, razão atribuída, por muitos, entre os fato- 
res que dificultavam o ensino de História da África e Cultura Afro-Brasileira. Zelinda Barros cunhou a expressão "etnicidade virtual" para tratar das implicações da formação à distância para o ensino de história e cultura afro-brasileira. Ela se preocupou com a inclusão de conteúdos e a reformulação dos currículos para atender à legislação, concebendo "a etnicidade virtual como um fenômeno de produção e reprodução de diferenças no ciberespaço, construídas a partir do compartilhamento de representações de descendência e cultura comuns a determinado contingente humano" (BARROS, 2013, p. 136)

O caráter de denúncia social também é perceptível em livros que tratam dessa temática. Segundo Maria Nazaré Mota de Lima:

Reflexões sobre identidades, cultura, dupla consciência são importantes para a compreensão do negro e sua abordagem na escola, porque informam sobre como somos vistos, como somos tratados, os papéis sociais que desempenhamos ou deveríamos desempenhar na sociedade brasileira, influenciando relações de poder. (LIMA, 2015, p. 54).

Ao tempo em que contribui para problematizar as situações trazidas pelos professores, a bibliografia instiga a pensar sobre a dinâmica que acontece nas escolas, e não em como os(as) estudiosos(as) gostariam que elas fossem. Por outro lado, as discussões sobre a implementação da Lei 10.639/03, em diversos momentos, enfatizam a inclusão de conteúdos escolares, revelando a abordagem sobre currículo entendido como conjunto de conteúdos, que faziam referência a um somatório de culturas.

Ao enfrentar o debate das relações étnico-raciais na escola, fugindo da armadilha de fixação das identidades, foi importante o tratamento do currículo como "espaço-tempo híbrido de fronteira, ele é também uma arena em que se dá uma experiência colonial entre culturas que se legitimam de forma diferenciada" (MACEDO, 2006, p. 292). Nessa perspectiva de currículo, os binarismos são evitados e destaca-se uma compreensão de colonialismo em que estamos inseridos, portanto deixam de fazer sentido oposições acionadas para nomear o outro.

Não existe a presença de uma identidade negra que possa ser transmitida como conteúdo fixo, repetido, enquanto cópia do mesmo; trata-se de interrogar o passado, que se pretende repetir na escola, como uma história continuísta supostamente comum, que ajuda a constituir a crença em uma identidade cultural totalizante, reconhecendo as projeções identitárias como projetos de assujeitamento de singularidades subjetivas a regras e modelos predefinidos em um sistema de classificação. Trata-se também de reconhecer que qualquer projeto é contingente, falho, impossível (PONTES, 2015, p. 35).

O Projeto Maracujá não tinha como foco a relação de adolescentes da comunidade quilombola com a escola, mas ainda assim a convivência com os estudantes trouxe à tona o incômodo destes com o lugar que ocupavam no espaço escolar. O docudrama \#vamosfazerumfilme? nasce, portanto, contaminado com a experiência de estudantes, pesquisadores, moradores e gestores municipais que, em situações diversas, questionavam o papel da escola no atendimento às demandas daquela comunidade.

As experiências vividas no Maracujá indicam a necessidade de "des-locar" os saberes, em um exercício de desconstrução que considere os trânsitos, realinhamentos e deslocamentos, aproximando-se de uma "forma ubíqua de viver a localidade da cultura", em que as brechas atuariam como tradução cultural (BHABHA, 2010, p. 199). Em outras palavras, foi possível perceber a necessidade de inserção dos saberes locais na escola, não como um leque de curiosidades ou apêndices, e sim considerando as temáticas cujos efeitos de significados disputam sentidos na comunidade, ao tempo em que dialogam (certamente de forma conflituosa) com saberes hegemonizados pelas políticas curriculares, evidenciando as tensões que envolvem a produção do conhecimento.

\section{“Mãe, ser quilombola é ser bicho?”}

Numa reunião com pais e mães de estudantes da Escola A, a pergunta acima foi citada por uma mãe que atua nos movimentos sociais e dividiu a sua angústia diante da situação vivenciada por sua filha naquela instituição, indicando que as questões relacionadas às comunidades quilombolas não eram discutidas. $\mathrm{O}$ questionamento daquela criança evidencia a dificuldade em compreender o termo quilombola, visto como algo negativo, a partir 
de algumas pistas que suas experiências naquele espaço constituíram.

Naquela reunião, os adultos mostraram o seu incômodo com o tratamento recebido na sede do município de Nordestina. Toda aquela região é conhecida popularmente como Poças, nome de uma das comunidades quilombolas. Situações de violência são frequentemente associadas às Poças. Jovens presentes naquela conversa relataram que costumam informar outro endereço, pois afirmar que mora nas Poças dificultaria o acesso ao crédito financeiro e à oferta de emprego.

No que diz respeito especificamente à escola, o diretor da instituição nos diz que os docentes costumam ser transferidos para a Escola A como “castigo". Ele mesmo teria vindo após uma eleição municipal, em que o candidato apoiado por ele saiu derrotado no pleito. Relatos semelhantes foram ouvidos em outras escolas quilombolas do Território.

Essas narrativas foram emergindo em atividades do Projeto de Extensão "Experiência, formação e práticas curriculares em escolas quilombolas no Território do Sisal". ${ }^{6}$ O projeto iniciou em 2014, atuando inicialmente com docentes de Conceição do Coité. De lá até 2016, alterações significativas ocorreram na proposição inicial, que conduziram à realização de rodas de conversa com comunidades quilombolas e profissionais, incluindo no campo da pesquisa o município de Nordestina.

Nas conversas com lideranças das comunidades, a proposta de atuar na formação de professores em exercício foi bem recebida, ainda que a justificativa para a boa acolhida traga algumas inquietações. Há expectativa de que a formação contribua para a positivação das práticas culturais associadas à população negra, auxiliando nas lutas por direitos. Uma legitimação que envolve uma narrativa homogênea do passado comum de escravidão e ligação direta com as mazelas sociais contemporâneas, que compõem textos de afirmação identitária (PONTES, 2015).

Para algumas lideranças, a formação dos professores, inevitavelmente, possibilitaria a construção de parcerias, na árdua tarefa de auxiliar as

6 Agradeço às estudantes que fizeram parte da equipe da pesquisa como bolsistas e voluntárias: Bárbara Anunciação, Geniclécia Lima dos Santos, Grazielle Barbosa, Jamara Santos, Juliana Mutti, Kamila Mestre, Milena Sant'ana, Rayla Roberta Silva de Oliveira e Rosiler Santos. pessoas da comunidade a tomar consciência sobre o que é ser quilombola. Um entendimento de que a população do Território do Sisal carrega uma ancestralidade comum que lhe garantiria identidade (MACEDO; PEREIRA, 2009).

Entretanto, o projeto de extensão não tem uma explicação definitiva e essencialista do que é ser quilombola e tampouco tem a pretensão de ensinar aos moradores de comunidades rurais do Território como é ser quilombola. Discordamos, como Paul Gilroy (2001), da perspectiva que vê a comunidade no caminho errado, como se o papel dos estudiosos fosse indicar a trajetória correta, "uma nova direção, primeiramente pelo resgate e, depois, pela doação da consciência racial de que as massas parecem carecer" (GILROY, 2001, p. 86). Longe disso, interessa rasurar o termo quilombo, abrindo mão de idealizações e suposições prévias, para então atuar nas comunidades quilombolas tais como se apresentam naqueles municípios.

Ao longo do desenvolvimento do projeto de extensão foi necessário ampliar as leituras sobre práticas educativas envolvendo crianças e adolescentes quilombolas. A consulta ao banco de teses e dissertações da Capes em 2016 indicou um número tímido de produções sobre "educação escolar quilombola". Constam registros de 23 trabalhos concentrados em universidades da Bahia, Rio de Janeiro, Paraná e Rio Grande do Sul. Os textos foram defendidos em programas de pós-graduação de artes cênicas, crítica cultural, ciências humanas e sociais, políticas públicas e, majoritariamente, em educação (19 textos).

Muitos pesquisadores destacam que a escola deve incorporar em suas práticas elementos que compõem contexto dos estudantes, especialmente quanto aos aspectos culturais. Larchert (2014, p. 43) fala do papel da escola para o "resgate e a ressignificação da matriz da cultura africana". Givânia Silva chama atenção para a necessidade de ouvir as comunidades na organização dos currículos e na construção de metodologias para as aulas, atentando para os significados que os moradores atribuem à educação (SILVA, 2012).

As pesquisadoras propõem uma relação diferenciada com as comunidades, possibilitando o ingresso das temáticas do seu interesse e dos seus saberes no espaço escolar, nas palavras de Mille 
Caroline Fernandes: "É preciso pensar uma escola que dê condições para que jovens negros se vejam inseridos no contexto escolar e que sua cultura seja valorizada de forma que fortaleça seus marcadores identitários" (FERNANDES, 2013, p. 191).

Entretanto, entendendo a escola como uma instituição moderna, vista como o espaço de sistematização e transmissão de conhecimentos, haveria formas de inserção da cultura local, distintas daquelas que os pesquisadores criticam? Ou seja, em datas comemorativas e, por vezes, numa perspectiva folclórica. Em alguns momentos, fica a sensação de que as escolas, após a realização de ações isoladas, sentem-se aptas para carregar um balãozinho, semelhante ao que passamos a ver nos livros didáticos de história, na sanha editorial para se mostrar cumpridora dos padrões legais: "De acordo com a Lei 10.639/03"!

Mais uma vez aparece a ideia de que basta a inclusão de conteúdos para proporcionar educação atenta às questões étnico-raciais. Ao tratar o problema pelo viés da inclusão de conteúdos, desponta uma compreensão de currículo como listagem de conteúdos pensada por uns e executada por outros, na contramão das discussões sobre práticas curriculares referenciadas ao longo desse texto. Além disso, chama atenção a perspectiva de currículo como repertório, numa ideia de cultura como coisa (MACEDO; PEREIRA, 2009).

Entre outros problemas, essa compreensão propõe um remendo; ao fazê-lo, abrimos mão de enfrentar uma questão mais ampla: qual é o papel da escola no pensar a diferença? A palavra "resistência", por exemplo, tem uso corriqueiro nas discussões sobre educação escolar quilombola, enquanto a problematização sobre o ser quilombola, algo tão latente nas comunidades do Território, não aparece com tanta frequência. A ênfase é dada ao aspecto combativo. Por vezes, as discussões indicam os quilombolas como pessoas essencialmente batalhadoras, exceto por alguns detalhes que vão surgindo ao longo das narrativas. Na tese Resistência e seus processos educativos na comunidade negra rural Quilombola do Fojo (LARCHERT, 2014), percebe-se que a questão da identidade envolve questões mais complexas do que podemos pressupor ao ler o título. Nesta construção identitária, assumir-se quilombola é conflituoso e de difícil autodenominação; os moradores da comunidade negra rural do Fojo preferem a identificação como nativos, pois sequer conhecem o que o termo quilombola significa. $\mathrm{O}$ significado da palavra quilombo tem sido de difícil apropriação para a comunidade, historicamente reconhecida e autorreconhecida como comunidade de nativos de Itacaré. A categoria "nativo" diz do negro enraizado em terras do município pertencente às famílias originárias do Quilombo do Oitizeiro. É comum ouvir dizer: "eu sou nativo do Oitizeiro" (LARCHERT, 2014, p. 143).

Diante da dificuldade enfrentada pelos estudantes, mães e profissionais que atuam nas escolas quilombolas em assumir essa adjetivação, vista por muitos como algo pejorativo, proponho rasurar o termo quilombola. E, para tanto, a distinção entre quilombos históricos e contemporâneos foi um passo importante na contramão das idealizações (ARRUTI, 2006; REIS; GOMES, 1996). Nesse sentido, a rasura pode ser pensada como a desconstrução de "quilombo", no sentido de operar no deslizamento, sem oposição, entre o quilombo de luta e resistência e o quilombo do constrangimento e da negação que aparece de forma tão intensa nas falas de moradores do Território (DERRIDA, 1991).

Ao perceber que, em outras comunidades, ocorre a mesma dificuldade dos moradores com o ser quilombola, retomo a pergunta reproduzida pela mãe da aluna: "Ser quilombola é ser bicho?". A fala apareceu quando questionávamos a relação dos docentes da Escola A com o seu entorno. Em tom de denúncia, a mãe apontava que a escola não ensinava aos estudantes o que era ser quilombola e que ela também não se sentia à vontade para responder àquela questão. $\mathrm{O}$ apelo era para que a escola dissesse à comunidade o que ela é.

$\mathrm{Na}$ bibliografia consultada, pesquisadores(as) também indicavam o silenciamento das instituições escolares, tratado como omissão diante de temáticas e dinâmicas locais. Entretanto poderíamos questionar se o incômodo não se dá porque a escola não tem sido uma parceira na construção dessas comunidades imaginadas como espaços de luta e resistência. A escola não tem contribuído suficientemente para que "nativos" se sintam confortáveis ao serem denominados quilombolas? Nesse caso, cobra-se uma desconstrução da escola, para que esta incorpore de forma estruturante, na sua prática 
curricular, a memória, história e culturas locais, ou o anseio é pelo reforço da escola moderna que teria o papel de iluminar a comunidade, respondendo a sua vontade de saber quem ela é?

O tratamento do currículo, como uma prática de "negociação-com-a-diferença" (MACEDO; PEREIRA, 2009, p. 127), se opõe à compreensão de cultura como resistência e somatório. Nesse sentido, a indicação que a escola incorpore novos conteúdos, que trate da história e cultura afro-brasileira e africana, conforme propõe a Lei 10.639/03, ou ainda as orientações presentes nas Diretrizes Nacionais para Educação Escolar Quilombola, não contribui para problematizar a escola, pontuando o lugar da diferença nessa instituição. A proposta solicita um reparo e, ao apontar a necessidade de implementação desses dispositivos legais, permanece o debate sobre identidade no espaço escolar, reforçando a cantilena de que a escola é para todos, ignorando o contexto de extremas desigualdades historicamente construídas (MACEDO, 2013). Como indica Carlos Skliar (2010, p. 209-210), na escola moderna, "O mesmo e o outro não podem, nessa temporalidade, nessa escola, estar ao mesmo tempo. A mesmice da escola pró́be a diferença do outro".

\section{“Pró, eu tenho uma coisa pra te ensinar"}

As escolas que atendem as comunidades quilombolas de Nordestina e Conceição do Coité estão localizadas em povoados relativamente próximos à sede dos municípios e são consideradas escolas do campo pelos gestores. O envolvimento destes com os movimentos sociais do Território do Sisal e a proximidade com os debates acadêmicos evidenciam-se na compreensão de que é direito da população ter acesso à educação no lugar em que vive e ligada às suas práticas culturais e sociais (ARAÚJO; NASCIMENTO, 2006). Nesse sentido, compreende-se educação do campo como "forma contextualizada de percepção [que] tem, no saber de homens e mulheres do campo, um dos seus pilares de sustentação" (RANGEL; CARMO, 2011, p. 209).

Nordestina e Conceição do Coité são municípios predominantemente rurais. Com o intuito de atender à demanda dos movimentos sociais e determinações legais, como as "Diretrizes Operacionais para Educação Básica nas Escolas do Campo", publicada em 2002, estabeleceu-se a parceria entre as redes municipais de educação e o Movimento de Organização Comunitária (MOC).

O MOC surgiu em 1967, ligado aos trabalhos sociais da Igreja Católica. Em 1970 ganhou autonomia em relação à Igreja e passou a realizar ações voltadas para o desenvolvimento sustentável da região, apoiando organizações sociais e associações comunitárias rurais. No final da década de 1990 intensificou-se o trabalho com educação popular e formulou-se o Projeto CAT - Conhecer, Analisar e Transformar a realidade do semiárido, pautado na perspectiva de Paulo Freire da ação-reflexão-ação, que atualmente conta com a participação de docentes da Universidade Estadual de Feira de Santana (SILVA; CARVALHO, 2015).

Pautado nas dimensões do conhecimento, estética, ambiental e dos relacionamentos humanos, o CAT atua na formação em exercício de professores da rede, que são acompanhados no planejamento de suas atividades ao longo do ano letivo. Com base na concepção crítica de currículo, o projeto propõe educação contextualizada que valoriza as experiências de estudantes e professores no semiárido e propõe melhorias às suas condições de vida. Em um material destinado aos professores sobre educação contextualizada, uma das coordenadoras do CAT afirma:

Diante desses dados, constatamos a necessidade de se fazer uma educação que contribua para a construção do desenvolvimento local sustentável como um processo no qual a escola seja um espaço onde seus educandos e educandas construam uma imagem positiva do Semiárido; como um lugar possível e bom de vida, de cultura e de direitos, desmontando estereótipos como 'homem sertanejo fraco', 'terra seca e improdutiva' e garantindo o sucesso das crianças na escola e a sua permanência na região. Ou seja, torna-se necessário um currículo onde o Semiárido seja visto como uma região de possibilidades e sustentabilidade. (SOUZA, 2013, p. 28-29).

Somente em 2004 construiu-se o Plano Territorial de Educação do Campo, com aprovação de lei na maioria dos municípios que compõem o Território. Desde então, o Programa tornou-se política 
pública, tendo uma autonomia maior diante das turbulências ocorridas nos momentos de mudança na gestão municipal. Diante disso, o tratamento dado à educação do campo nesse texto refere-se especificamente às práticas conduzidas pelo MOC, com o Projeto CAT. Esse recorte foi realizado em face da importância atribuída ao CAT pelos(as) professores(as) e gestores(as) entrevistados(as), resultado da inserção do MOC nas redes municipais do Território.

O CAT propõe que o planejamento dos professores seja dividido entre três etapas: conhecer, analisar e transformar. $\mathrm{O}$ primeiro momento da relação com os estudantes é o "conhecer", no qual os docentes promovem atividades que possibilitem acesso à realidade dos estudantes. O segundo momento é o "analisar", quando cabe à escola partir das informações coletadas no primeiro movimento e apresentar informações sistematizadas pela educação formal. Ao fazer isso, a escola cumpriria o seu papel de promover acesso ao conhecimento sistematizado. Finalmente, viria o "transformar", momento em que a escola apresenta uma proposição para a comunidade, visando à melhoria das condições de vida dos envolvidos e não apenas para os estudantes.

Para o entendimento da dinâmica das aulas nas redes municipais, coletamos as "fichas pedagógicas" produzidas por professores e coordenadores pedagógicos para o ano letivo de 2015. As escolas organizam as aulas em quatro unidades e para cada uma delas é elaborada uma ficha. As fichas são estruturadas da seguinte maneira: tema (único para as todas as unidades), subtema, justificativa, objetivo geral, procedimentos metodológicos e passos metodológicos divididos em conhecer, analisar e transformar. As fichas apresentam o planejamento para todas as turmas e disciplinas do Ensino Fundamental I.

Nas conversas com equipes de Secretarias de Educação, também tivemos acesso à informação de que a ficha pedagógica é elaborada previamente e ajustada com os professores. Dias depois da reunião, as fichas são enviadas para todos os docentes da rede municipal via e-mail e há uma expectativa por parte das Secretarias de que elas sejam cumpridas, o que é verificado no momento chamado de "devolutiva".
Encontramos posicionamentos diferenciados quanto ao uso da metodologia proposta pelo CAT. Nas visitas às escolas de Conceição do Coité, ouvimos queixas relacionadas à elaboração das fichas e ao uso do livro didático, que é escolhido pelos professores. Alguns docentes assumiram que deixam o planejamento de lado e trabalham à sua maneira; outros tinham a mesma postura em relação ao livro didático. Ao entrevistar a professora Rosa, questionei sobre a participação dos professores na elaboração das fichas pedagógicas do CAT e obtive a seguinte resposta:

Geralmente eles trazem uma anterior pronta. Aí você só faz ver se tá bom, se tá legal, se você acrescenta alguma coisa, se não. Eles trazem um trabalho pré pronto e o professor pode, sim, ajudar [...] E assim, se você disser: 'Eu não achava interessante trabalhar com esse tema, mas trabalhar com outro'. Pode ter certeza que o tema que você não queria vai tá lá. (ROSA).

$\mathrm{O}$ incômodo apresentado por Rosa indica a disputa por autonomia envolvendo professores e Secretaria de Educação. Nas falas das coordenadoras pedagógicas que atuam na Secretaria (do mesmo município em que Rosa atua), a elaboração das fichas, atendendo a essa metodologia, permite a padronização do trabalho realizado na rede. Nas falas da equipe que coordena o CAT, identificamos um grande entusiasmo com a proposta:

Aí começou a minha experiência com os meninos. [...] Teve um dia que uma aluna me disse: 'Pró, eu tenho uma coisa pra te ensinar', e me abraçou. Pronto! Meu horizonte se abriu, porque é isso que o CAT propunha: Que os estudantes têm muito a ensinar, que o conhecimento que eles produzem, que a comunidade produz, é rico e precisa ser valorizado em sala de aula (ANGÉLICA).

Fica evidente na fala de Angélica a sua ligação com a educação do campo, diretamente relacionada às suas experiências. Entretanto, a maioria das professoras da mesma rede não apresenta tamanha implicação com a educação do campo e, também, por isso tecem severas críticas à adoção do CAT, que na primeira rede pesquisada foi adotada em todas as escolas do campo, numa decisão tomada pela Secretaria Municipal de Educação. Para aqueles que se opõem, a metodologia diferenciada tira 
oportunidades dos estudantes dos povoados, que teriam acesso a uma "quantidade menor de conteúdos”, quando comparados aos discentes da sede.

Todos esses conflitos ajudam a compreender o contexto de produção das fichas, o seu uso e desuso pelas professoras. Sobre isso, Rosa afirmou:

Quando eu trabalhei as histórias locais mesmo, as histórias de vida dos alunos e a história de vida dos avós, aí a gente pode conhecer um pouco mais sobre eles. [...] Então, o CAT, ele existe. A gente não consegue colocar ele em prática em todos os assuntos, entendeu? [...] Quando a gente retrata mesmo um assunto de História, que a gente vai pra história dos livros, né? Que houve essa necessidade de a gente fazer as indagações da descoberta do Brasil, das Capitanias Hereditárias. Então a gente não usou nada de CAT. O CAT nesse momento foi esquecido (ROSA).

Ao longo da entrevista, a professora vai indicando as situações em que a metodologia do CAT é considerada apropriada para o uso, quando se refere às "histórias locais", e os momentos em que ele fica esquecido, partindo-se, então, para as "histórias dos livros". A oposição apresentada por essas duas histórias revela a dificuldade de articulação entre os conhecimentos da história local e os conteúdos presentes no livro didático. A escolha por "abandonar" as indicações contidas na ficha do CAT está relacionada à compreensão de que os alunos deixariam de acessar informações consideradas pela docente como fundamentais, e entre as citadas estaria a narrativa sobre a chegada dos europeus ao Brasil e a primeira divisão administrativa da colônia.

A oposição presente na fala da professora Rosa entre "as histórias locais" e "a história dos livros" evidencia a intenção de produzir conhecimento nas escolas voltado para a realidade em que vivem os estudantes e com um potencial de transformar suas comunidades, numa perspectiva moderna do papel da escola. Nela, os saberes prévios dos estudantes, reunidos no momento do "conhecer", só fazem sentido se, ao final do processo, forem "transformados", uma transformação cujos moldes não são definidos pela comunidade. Uma perspectiva racionalista da emancipação, que apresenta o dilema de uma dicotomia absoluta, gerada num ato de fundação radicalmente revolucionário (LACLAU, 2011).
A narrativa da professora vai delineando a sua prática como instituinte do currículo, que dialoga com as tentativas de controle, encontrando táticas para garantir a sua autonomia. Independente dos temas trabalhados ao longo da unidade, "Quando vai chegando perto da data da devolutiva é que você pega o tema e trabalha um pouquinho, pra ficar fresco assim pros meninos e aí apresenta na devolutiva" (ROSA). A despeito das tentativas de controle que vão do planejamento, supostamente coletivo, ao momento da fiscalização, a professora indica suas táticas para tecer o currículo no seu cotidiano.

Uma prática curricular consistente somente pode ser encontrada no saber dos sujeitos praticantes do currículo, sendo, portanto, sempre tecida, em todos os momentos e escolas. Nessa perspectiva, emerge uma nova compreensão de currículo:

Não estamos falando de um produto que pode ser construído seguindo modelos preestabelecidos, mas de um processo através do qual os praticantes de currículo ressignificam suas experiências a partir das redes de poderes, saberes e fazeres dos quais participam. (ALVES et al., 2011, p. 41).

Entendida dessa forma, histórias, práticas e saberes locais negociam seu ingresso na escola não a partir da oposição entre hegemônico e subalterno, cultura erudita e popular, conhecimentos eurocêntricos e decoloniais, pois tais oposições não contemplam a complexidade do cotidiano. As práticas curriculares contaminam-se do local, apesar dos esforços de homogeneização e controle, gerando uma tensão entre repetição e performatividade, no espaço-tempo limiar (BHABHA, 2010).

Esse trânsito entre as Secretarias de Educação, docentes e MOC permitiu perceber os contornos locais das disputas estabelecidas pelas práticas curriculares no Território do Sisal. Interessa, especialmente, o saber experiência como existência, nos termos de Larrosa Bondiá (2002, p. 27): “A experiência e o saber que dela deriva são o que nos permite apropriar-nos de nossa própria vida". A experiência sendo tratada como "aquilo que nos acontece” (LARROSA BONDIÁ, 2002, p. 20). Nesse sentido, retoma-se o questionamento feito anteriormente: como as práticas sociais e culturais das comunidades quilombolas do Território contaminam as escolas? 
Propor que ocorram intersecções entre práticas curriculares contextualizadas da educação do campo e a atenção ao processo de constituição identitária - entendido de forma ubíqua, múltipla e complexa - das comunidades quilombolas indica possibilidades de estabelecer a experiência como elemento fundante na formação de estudantes do Território. Isso permitiria que as práticas culturais e sociais que fazem parte da experiência dos(as) estudantes ingressassem cotidianamente na escola, e não como curiosidade em datas comemorativas.

\section{Considerações finais}

O contato com moradores das comunidades quilombolas do Território e professores nas escolas que atendem a esta população levou a situá-las no entre-lugar. $\mathrm{O}$ termo quilombo foi lido como o que designa movimentos de luta/resistência e como referência para pensar em vergonha/ negação, deslizando nesse limiar.

Nessa indecibilidade, mães, professores, estudantes e lideranças questionam o papel da escola e, ao fazê-lo, não estão sozinhos; pesquisadores denunciam silenciamento nas instituições escolares, valendo-se de dispositivos legais recentemente conquistados pelo movimento negro e pelos educadores do campo. Entretanto, faz-se necessário atentar aos "praticantespensantes" que atuam nas escolas e os "modos de fazer" currículo. Por isso as buscas por práticas culturais, memória e fazeres locais se dirigem às subversões e não aos instrumentos de normatização das instituições escolares.

Nesse sentido, propõe-se pensar o currículo como espaço de construção discursiva e agenciamento de experiências no cotidiano escolar, numa defesa de que não há "identidade cultural para ser descoberta ou nomeada" e "identidade como uma construção discursiva culturalmente específica" (MACEDO; PEREIRA, 2009, p. 123).

A relação estabelecida entre a UNEB - Campus $\mathrm{XIV}$ e as prefeituras do Território do Sisal tem proporcionando cenários formativos para tratar de práticas curriculares. Ao seguir rastros nas teias de significação construídas nos processos formativos que enredam pesquisadora, estudantes e professores(as), por vezes, foram borrados os lugares pré-estabelecidos pela etnografia, para observador e observado, possibilitando operar no deslizamento do termo quilombola para problematizar práticas curriculares que radicalizem o debate sobre o lugar da diferença na escola, atentando para ações de docentes, vistos como "praticantespensantes" que negociam cotidianamente com instrumentos normativos e saberes sistematizados, ao tempo em que contaminam os seus fazeres pela comunidade em que se inserem as escolas e/ou das quais partem os estudantes.

\section{REFERÊNCIAS}

ALVES, Nilda. Et al. Criar currículo no cotidiano. 3. ed. São Paulo: Cortez, 2011.

ARAÚJO, Sandra R. M; NASCIMENTO, Antônio D. Escola para o trabalho, escola para a vida: o caso da Escola Família Agrícola de Angical - Bahia. Revista da FAEEBA - Educação e Contemporaneidade, Salvador, v. 15, n. 26, p. 97-114, jul./dez. 2006.

ARRUTI, José. M. A emergência dos remanescentes: notas para o diálogo entre indígenas e quilombolas. Mana, Rio de Janeiro, v. 3, n. 2, p. 7-38, out. 1997.

Mocambo. Antropologia e História do processo de formação quilombola. Bauru, SP: Edusc, 2006.

BARROS, Zelinda dos S. Implicações da formação a distância para o ensino de história e cultura afro-brasileiras. 2013. 230 f. Tese (Doutorado em Estudos Étnicos e Africanos) - Programa de Pós-Graduação Multidisciplinar em Estudos Étnicos e Africanos da Universidade Federal da Bahia, Salvador, 2013.

BHABHA, Homi K. O local da cultura. Belo Horizonte: Editora UFMG, 2010.

BRASIL. Presidência da República. Decreto no 4.887, de 20 de novembro de 2003, que "Regulamenta o procedimento para identificação, reconhecimento, delimitação, demarcação e titulação das terras ocupadas por remanescentes das comunidades dos quilombos de que trata o art. 68 do Ato das Disposições Constitucionais Transitórias". Brasília, DF, 2003. Disponível em: <http://www.planalto.gov.br/ccivil 03/decreto/2003/d4887.htm>. Acesso em: 15 dez. 2016. 
CARVALHO, Maria Inez. O a-con-te-cer de uma formação. Revista da FAEEBA - Educação e Contemporaneidade, Salvador, v. 1, n. 1, p. 159-168, 1992.

DERRIDA, Jacques; ROUDINESCO, Elisabeth. De que é amanhã: diálogo. Rio de Janeiro: Zahar, 2004.

DERRIDA, Jacques. Margens da Filosofia. Campinas, SP: Papirus, 1991.

DUSCHATZKY, Silvia; SKLIAR, Carlos. O nome dos outros. Narrando a alteridade na cultura e na educação. In: LARROSA BONDIÁ, Jorge; SKLIAR, Carlos. Habitantes de Babel: poéticas e políticas da diferença. 2. ed. Belo Horizonte: Autêntica, 2011. p. 119-138.

FERNANDES, Mille C. Mbaétaraca: uma experiência de educação de jovens quilombolas no município de Nilo Peçanha/BA. 2013. 220 f. Dissertação (Mestrado em Educação) - Programa de Pós-Graduação em Educação e Contemporaneidade da Universidade do Estado da Bahia, Salvador, 2013.

FERRAÇO, Carlos E; NUNES, Kezia R. Currículos, culturas e cotidianos escolares: afirmando a complexidade e a diferença nas redes de conhecimentos dos sujeitos praticantes. In: FERRAÇO, Carlos E; CARVALHO, Janete M. (Org.). Currículos, pesquisas, conhecimentos e produção de subjetividades. Petrópolis, RJ: DP\&A, 2013. p. 71-104.

FERREIRA, Antonio. O currículo em escolas quilombolas do Paraná: a possibilidade de um modo de ser, ver e dialogar com o mundo. 2014. 158 f. Tese (Doutorado em Educação) - Programa de Pós-Graduação em Educação da Pontifícia Universidade Católica de São Paulo, São Paulo, 2014.

FUNDAÇÃO CULTURAL PALMARES. Portaria nº 98, de 26 de novembro de 2007. Brasília, DF, 2007. Disponível em: <http://www.palmares.gov.br/sites/000/2/download/portaria98.pdf>. Acesso em: 15 dez. 2016.

GILROY, Paul. O Atlântico negro. Modernidade e dupla consciência. São Paulo: 34, 2001.

GORDIANO, Maiara A. Família, sociedade e economia em Conceição do Coité: um estudo a partir dos inventários post mortem 1872-1899. 2011. Monografia (Licenciatura em História) - Universidade do Estado da Bahia, Conceição do Coité, BA, 2011.

HALL, Stuart. Da diáspora. Identidades e mediações culturais. Belo Horizonte: Editora da UFMG, 2003.

LACLAU, Ernesto. Emancipação e diferença. Rio de Janeiro: UERJ, 2011.

LARCHERT, Jeanes M. Resistência e seus processos educativos na comunidade negra rural quilombola do Fojo-BA. 2014. 220 f. Tese (Doutorado em Educação) - Programa de Pós-Graduação em Educação do Centro de Educação e Ciências Humanas da Universidade Federal de São Carlos, São Carlos, SP, 2014.

LARROSA BONDIÁ, Jorge. Notas sobre a experiência e o saber da experiência. Revista Brasileira de Educação, n. 19 , p. 20-28, jan./abr. 2002.

LIMA, Maria N. M de. Relações étnico-raciais na escola: o papel das linguagens. Salvador: EDUNEB, 2015.

MACEDO, Elizabeth. Currículo como espaço-tempo de fronteira cultural. Revista Brasileira de Educação, v. 11, n. 32, p. 285-297, 2006.

. Currículo e hibridismo: para politizar o conceito de cultura. Educação em Foco, Juiz de Fora, v. 8, n. 1-2, p. 13-30, 2004.

. Equity and difference in centralized policy. Journal of Curriculum Studies, v. 45, n. 1, p. 28-38, Feb. 2013.

MACEDO, Elizabeth; PEREIRA, Maria Z. Currículo e diferença no contexto global. In: PEREIRA, Maria Zuleide; CARVALHO, Maria Eulina P.; PORTO, Rita de C. C. Globalização, interculturalidade e currículo na cena escolar. Campinas, SP: Alínea, 2009. p. 109-125.

MESSEDER, Marcos L. L. Dinâmica cultural e construção identitária: reflexões em torno de uma etnografia contemporânea. A Cor das Letras, Feira de Santana, BA, n. 14, p. 69-93, 2013.

MORAES, Alexandre de (Org.). Constituição da República Federativa do Brasil. 16. ed. São Paulo: Atlas, 2000.

NASCIMENTO, Abdias. Quilombismo. 2. ed. Brasília, DF: Fundação Cultural Palmares, 2002.

PONTES, Cassandra M. da Silveira. Precipitação curricular responsável: entre a estratégia e o limite singular da identidade negra. 2015. 175 f. Tese (Doutorado em Educação) - Programa de Pós-Graduação em Educação da 
Universidade do Estado do Rio de Janeiro, Rio de Janeiro, 2015.

RANGEL, Mary; CARMO, Rosângela Branca do. Da educação rural à educação do campo: revisão crítica. Revista da FAEEBA, - Educação e Contemporaneidade, Salvador, v. 20, n. 36, p. 205-214, jul./dez. 2011.

REIS, João José; GOMES, Flávio dos Santos. Liberdade por um fio: história dos quilombos no Brasil. São Paulo: Cia. das Letras, 1996.

RIOS, Iara Nancy Araújo. Nossa Senhora da Conceição do Coité: poder e política no século XIX. 2003. 155 f. Dissertação (Mestrado em História) - Faculdade de Filosofia e Ciências Humanas da Universidade Federal da Bahia, Salvador, 2003.

SANTANA, Carlos E. Pelejando e arrudiando. Processos educativos na afirmação de uma identidade negra em território quilombola: Baixa da Linha. 2015. 268 f. Tese (Doutorado em Educação) - Programa de Pós-Graduação em Educação da Universidade do Estado da Bahia, Salvador, 2015.

SILVA, Givânia M. da. Educação como processo de luta política: a experiência de "educação diferenciada" do Território Quilombola de Conceição das Crioulas. 2012. 199 f. Dissertação (Mestrado em Políticas Públicas e Gestão da Educação) - Programa de Pós-Graduação em Educação da Faculdade de Educação da Universidade de Brasília, Brasília, DF, 2012.

SILVA, Maria do S.; CARVALHO, Inaiá M. de (Org.). A educação contextualizada no semiárido baiano: a contribuição do projeto CAT para as políticas de educação e a escola do campo. Feira de Santana, BA: MOC/ Curviana, 2015.

SKLIAR, C. A educação que se pergunta pelos outros: e se o outro não estivesse aqui? In: LOPES, A.; MACEDO, E. (Org.). Currículo: debates contemporâneos. São Paulo: Cortez, 2010. p. 196-215.

SOUZA, Edimária L. O. Martinha: a história de uma ex-escravizada no sertão de Coité (1870-1933). 2016. $127 \mathrm{f}$. Dissertação (Mestrado em História Regional e Local) - Programa de Pós-graduação em História Regional e Local da Universidade do Estado da Bahia, Santo Antônio de Jesus, BA, 2016.

SOUZA, Maria de Lourdes A. de. Por que precisamos de um currículo contextualizado? In: DUARTE, Ana Paula; CARNEIRO, Vera M. O. (Org.). Contribuições para construção de um currículo contextualizado para o semiárido. Feira de Santana, BA: MOC/Curviana, 2013. p. 15-31. 